\title{
Design Analysis \& Performance Evaluation for Epicyclic Shaft Mounted Gearbox with Integrated Timer Belt Drive
}

\author{
Harshad S. Sidawadkar*, V. S. Mahajan* and Subim Khan ${ }^{\$}$

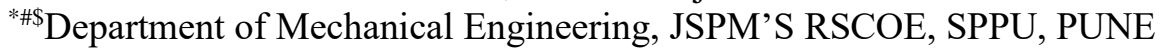

(Received 22 December 2020; Accepted 27 February 2021)

https://doi.org/10.36224/ijes.140102

\begin{abstract}
Machine spindle drives require high speed high torque transmission with constant velocity ratio (limited slip). Conventionally v-belt drive gives low efficiency and does not have constant velocity ratio. Commercial gearboxes like the worm gear drive spur or helical gear box needs a separate belt drive which makes the it bulky, space consuming and costly. More over by the application of worm gear box in many cases it is found that the transmission efficiency is drastically lowered. So there is a need of shaft mounted speed reducer to solve above problem. Project aims at development of an integrated timer belt drive Epicyclic shaft mounted gear box which will reduce the space consumption, improve efficiency of transmission as spur gears are used and timer belt drive will ensure constant velocity ration even at high speeds. Project work involves the kinematic design of the gear box, modeling of the components of the system using unigraphics nx-8 and analysis of components using ANSYS workbench 16.0 The test rig of the given gearbox will be manufactured and the testing of the system will be done for the performance characteristics.
\end{abstract}

Keywords: Integrated Timer Belt, Shaft mounted, Gear Box, Transmission Efficiency, Constant Velocity ratio

\section{Introduction}

Gear couplings like all other shaft coupling devices perform the basic functions of connecting two shafts to transmit torque and compensate for misalignment. Gear couplings though are the king of the coupling types. While each type of coupling has its own niche, gear couplings are more power intensive, have more modifications, and a wider size, torque, and bore range than all the others. Gear couplings can also perform at extremely high rates of speed. As inferred by the name, gear couplings use the meshing of gear teeth to transmit the torque and to provide for misalignments.

Gear couplings are made up of hubs which attach to the machinery shafts, and sleeves that span the gap from one hub to the next. Sometimes the sleeve is one piece as in the Sier-Bath \& HercuFlex continuous sleeve couplings and sometimes each hub has its own sleeve which in turn bolts to the other half or other side of the coupling. The gear teeth are found on both the hub and the sleeve of the flexible unit.

\section{Objectives}

Following are the objectives of this project:

i. To develop a Spot reduction arrangement using Internal spur gear.

ii. Integration of the spot reduction spur gear drive with a timer belt drive.

iii. Design \& analysis of components of the of the system using ANSYS workbench 16.0 
iv. Experimental analysis of System for performance characteristics.

\section{Literature review}

Govada Tejaswini \& G. Chandra Mohan Reddy [1] compared present technologies of the gearbox and the result of their calculated efficiency. From the comparison of various drives, they found that two stage cycloidal drives are having high efficiency (i.e. 92.7\%) as compared to the other drives.

Padmanabhan. S., Chandrasekaran M. and Srinivasa Raman. V., [2] developed Ant Colony Optimization for a Worm gear drive problem with multiple objectives. Within the various design variables available for a worm and worm wheel design, the power, weight, efficiency and centre distance have been considered as objective functions and bending stress, compressive stress as vital constraints to get an efficient compact and high power transmitting drive.

Chiu-Fan Hsieh [3] proposed a new transmission design for an eccentric speed reducer for which the internal and external gear profiles are constructed via a gear mathematical model and stress tested using a system dynamics analysis model.

Wan-Sung Lin [4] proposed the design of a new two-stage cycloidal speed reducer with tooth modifications.

Hong-Sen Yan \& Ta-Shi Lai [5] proposed Geometry design of an elementary planetary gear train with cylindrical tooth-profiles. They present a concept of elementary gear trains such that the toothprofiles of the pinion are cylindrical.

\section{Problem definition}

Present day Shaft mounted speed reducer available in market.

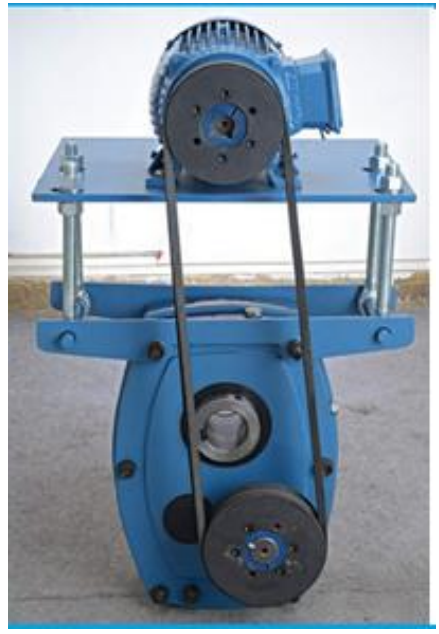

Figure 1: Problems with conventional device

This gear box although is shaft mounted still it will need a separate belt drive o be installed which will again increase the size and cost of the system, more over the worm gear pair used in the above gear box results in lower efficiency.

Worm gear boxes are popular choices for high speed reduction in many cases where there is limitation on space for power transmission. The worm gear box though gives high transmission ratios in small space the inhereent disadvantage is of very low transmission efficiency as shown below. 


\subsection{Energy losses from friction}

The efficiency for worm gear is calculated similarly to the screw mechanism.

When the worm is the driving element

$$
\eta=\frac{\tan \gamma}{\tan \left(\gamma+\rho^{\prime}\right)}
$$

And when the worm wheel is the driving element

$$
\eta=\frac{\tan \left(\gamma-\rho^{\prime}\right)}{\tan \gamma}
$$

With: $\quad$ : lead angle

$$
\rho^{\prime} \text { : apparent friction angle }
$$

The magnitude of the fiction coefficient in worm gear depends strictly on the quality of the surface treatment and the slip velocity, and can be read from the following chart [3][4].

The efficiency of worm gear depends on the coefficient of friction and the lead angle. Below we can see the diagram representing the dependency of the efficiency and those two parameters. In order to obtain a worm gear with high efficiency it is recommended to use the lead angle in the range between $15^{\circ}$ and $30^{\circ}$ [3] [4].

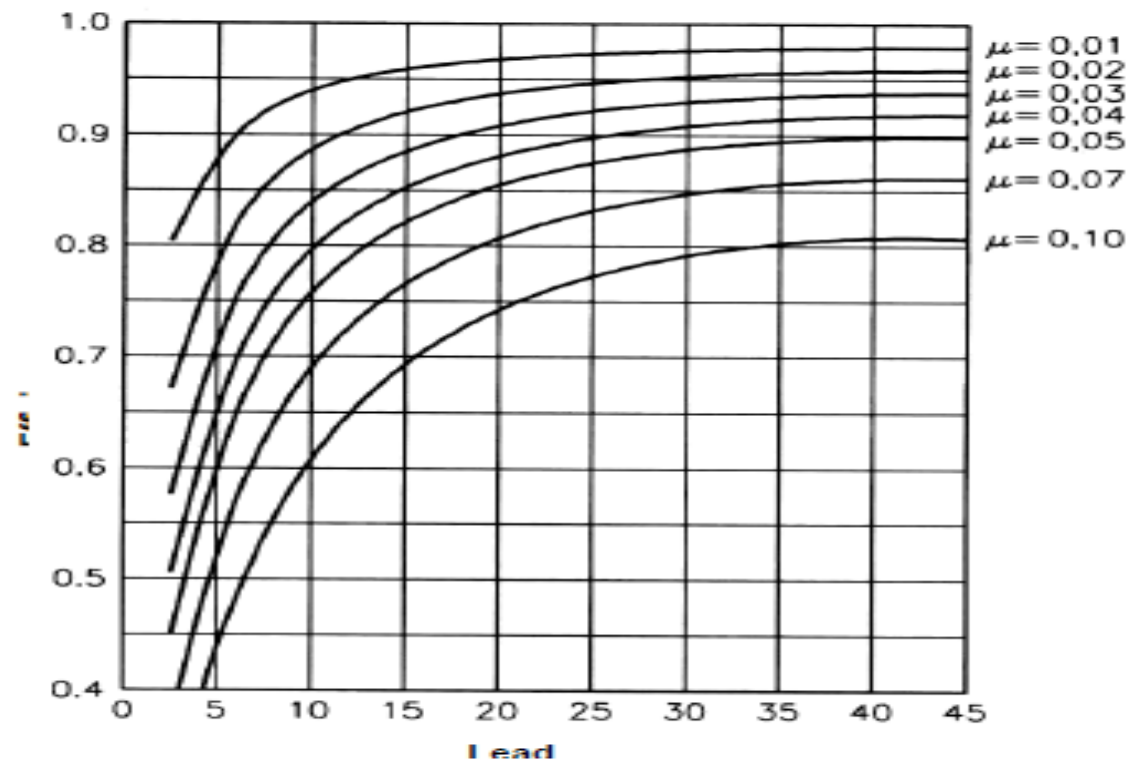

Figure 6. Efficiency vs. lead angle.

From the formula for calculating efficiency we can observe that it is possible to obtain a self locking worm gear when the following inequality holds:

$\gamma<\rho^{\prime}$

Figure 2: Relationship between Lead angle and Coefficient of friction

Therefore the lead angle must take very small values in between $1^{\circ}$ to $3^{\circ}$ which causes the efficiency to drop to below $50 \%$ and results in large energy losses and intensive heating of the worm gear. Self locking worm gears can operate only under small losses and interval work periods [4] [5]. 


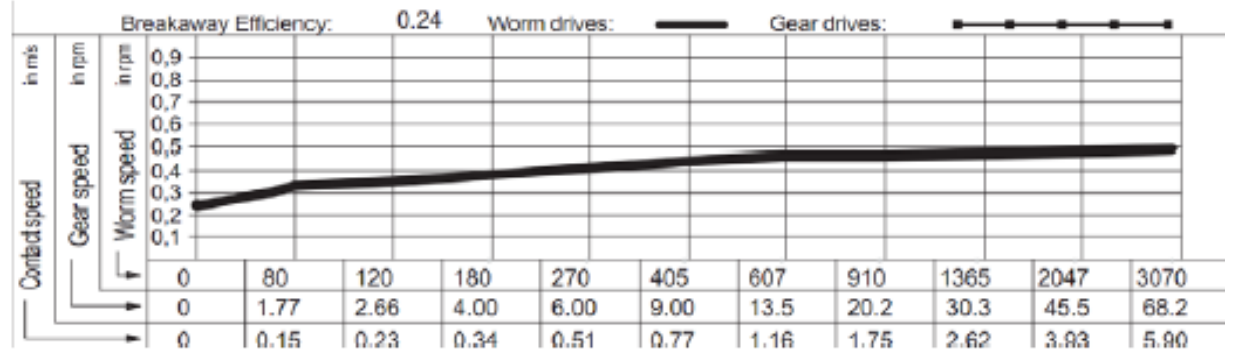

Figure 3: Efficiency of Worm gear box

Thus we can conclude that the if worm gear drives when used for lifting applications with self locking as the primary objective for safety considerations the drives are extremely in-efficient. Hence there is a need of special purpose drive that will provide better transmission efficiency in self locking condition so as to reduce power consume by the device i.e. lowering the running cost of device.

\section{Solution to Problem}

The solution to the above problem is in the form of shaft mounted gear reducer that can be mounted directly on motor shaft and spot reduction can be achieved in very low space. Shaft mounted speed reducer using high transmission efficiency compact internal external gear reduction gear box.

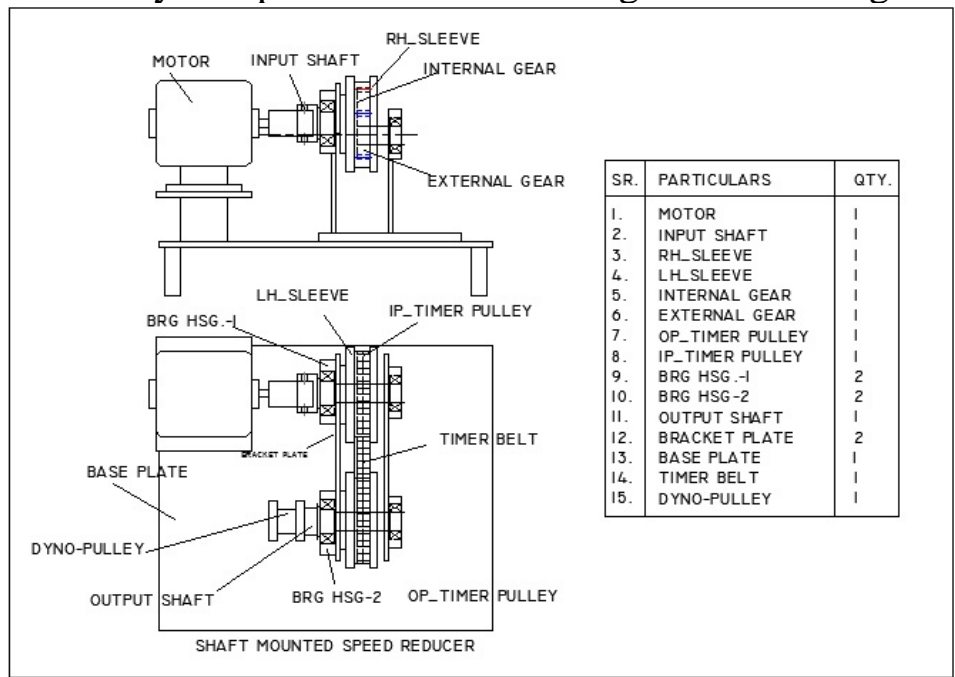

Figure 4: Concept of Shaft mounted Gear box with integrated Timer belt drive

The Main parts of the mechanism are as follow:

1. Input Shaft and Output Shaft

2. LH_Sleeve and RH_Sleeve

3. Input \& Output Timer Pulley

4. Internal Gear and External Gear 


\section{Construction}

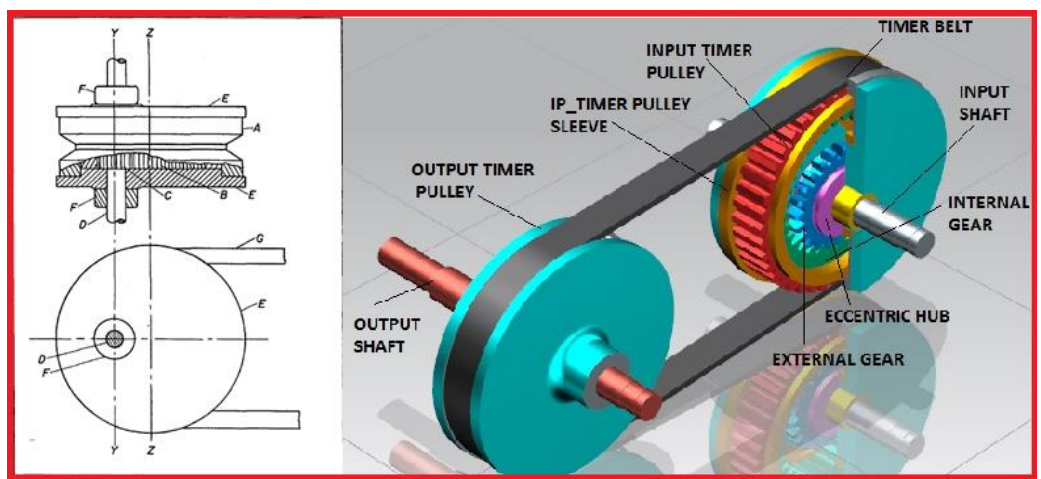

Figure 5: Construction of experimental setup for adjustable stroke mechanism

The shaft mounted speed reducer is a small cylindrical unit that mounts directly on the drive shaft and transmits power to the driven shaft (not shown) via a $v$ belt drive. The centre section on the speed reducer consists of a steel sleeve-A, internal gear $-\mathrm{B}$ and pinion-C. Internal gear $-\mathrm{B}$ is pressed into the steel sleeve where as the pinion- $\mathrm{C}$ which is keyed to drive shaft-D meshes with the gear. Two bronze liner end plates are turned to running fit into sleeve $-\mathrm{A}$. The bearing holes through which the shaft passes are located off centre by a distance necessary to provide proper engagement between the internal gear and pinion $\mathrm{C}$. Collars $\mathrm{F}$ are located adjacent to the end plates of sleeve $-\mathrm{A}$ and serve to retain the assembly intact. The unit can be packed with grease before assembly or a unit can be fitted for future Relubrication.

\section{Working Principle of Mechanism}

When the speed reducer is in operation there is a tendency for it to rotate with the shaft D about axis Y_Y but this proneness towards eccentric rotation is counteracted by pull of $\mathrm{V}$-belt $\mathrm{G}$ which restricts the rotation of sleeve A about axis Z-Z .A secondary effect of the tendency to rotate about axis Y_Y is that adequate tension is maintained on the v-belt on sleeve. If it is desired to hold the unit rigid a support arm can be provided from a point on machine to the end plates.

\section{Design and Analysis of Parts}

8.1. Design of Input Shaft:

Table 1: Material Selection: -Ref: - PSG (1.10 \& 1.24)

\begin{tabular}{|c|c|c|}
\hline Designation & Ultimate tensile strength $(\mathrm{N} / \mathrm{mm} 2)$ & Yeild strength $(\mathrm{N} / \mathrm{mm} 2)$ \\
\hline EN24 & 800 & 680 \\
\hline
\end{tabular}

As per ASME code $\mathrm{fs}_{\text {allowable }}=104 \mathrm{Mpa}$

$\mathrm{fs}_{\text {act }}=2.35 \mathrm{~N} / \mathrm{mm}^{2}$

As; $\quad \mathrm{fs}_{\mathrm{act}}<\mathrm{fs}$ all The Input shaft is safe under torsional load. 


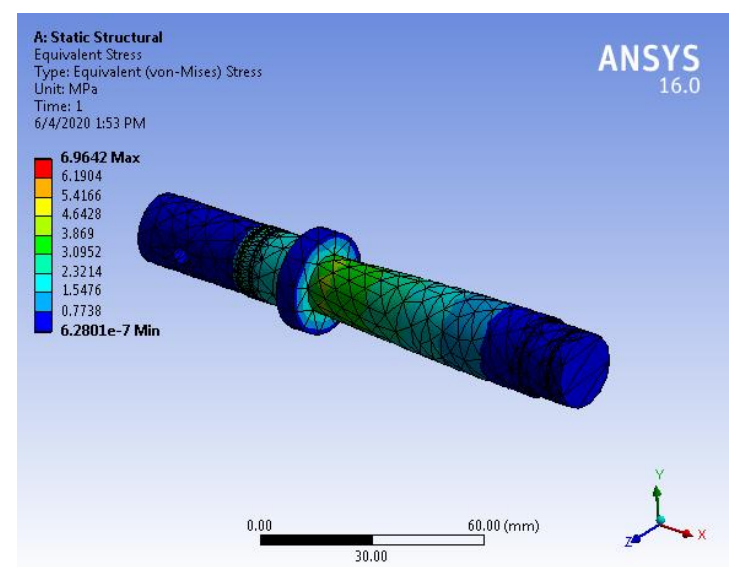

Figure 6: Maximum stress induced in the shaft

The maximum von-mises stress developed is $6.96 \mathrm{MPa}$ which is well below the allowable stress hence the worm shaft is safe under torsional load.

\subsection{Design of Input Pulley:}

Table 2: Material Selection: -Ref: - PSG (1.10 \& 1.24)

\begin{tabular}{|c|c|c|}
\hline Designation & Ultimate tensile strength $(\mathrm{N} / \mathrm{mm} 2)$ & Yeild strength $(\mathrm{N} / \mathrm{mm} 2)$ \\
\hline EN24 & 800 & 680 \\
\hline
\end{tabular}

As per ASME code fs allowable $=94 \mathrm{Mpa}$

Considering the gear ratio between the internal and external gear $=32 / 23$ the design torque Will be $\mathrm{Td}=$ $2170 \mathrm{~N}-\mathrm{m}$

Check for torsional shear failure of shaft

$\mathrm{Td}=\Pi / 16 \times \mathrm{fs}_{\text {act }} \mathrm{x}\left(\mathrm{D}^{4}-\mathrm{d}^{4}\right) / \mathrm{D}$

fs $_{\text {act }}=0.15 \mathrm{Mpa}$

As, $\quad \mathrm{fs}_{\mathrm{act}}<\mathrm{fs}_{\text {all }}$ The input pulley is safe under Torsional load.

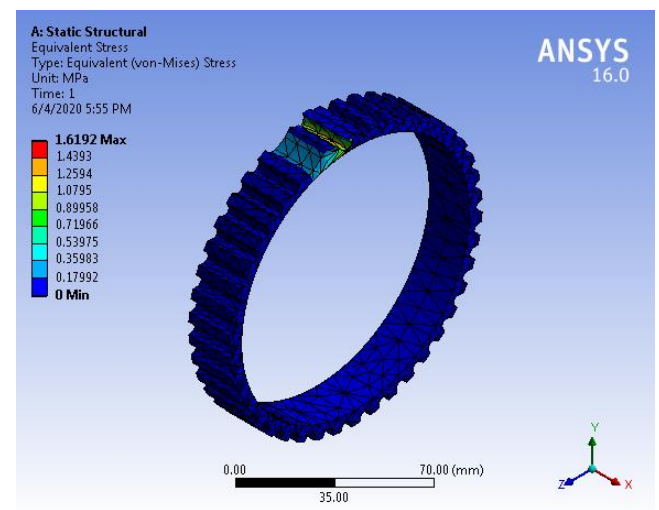

Figure 7: Maximum stress induced in the Input Pulley

The maximum stresses in the part are 1.61 MPa which is far below the allowable value $104 \mathrm{MPa}$ hence the part is safe under given loading conditions. 


\section{Experimental Method}

Following test are conducted during experimentation.

a) Torque VS. Speed Characteristics

b) Power VS. Speed Characteristics

c) Efficiency VS. Speed Characteristics

In order to conduct trial, a dyno-brake pulley cord, weight pan are provided on the output shaft.
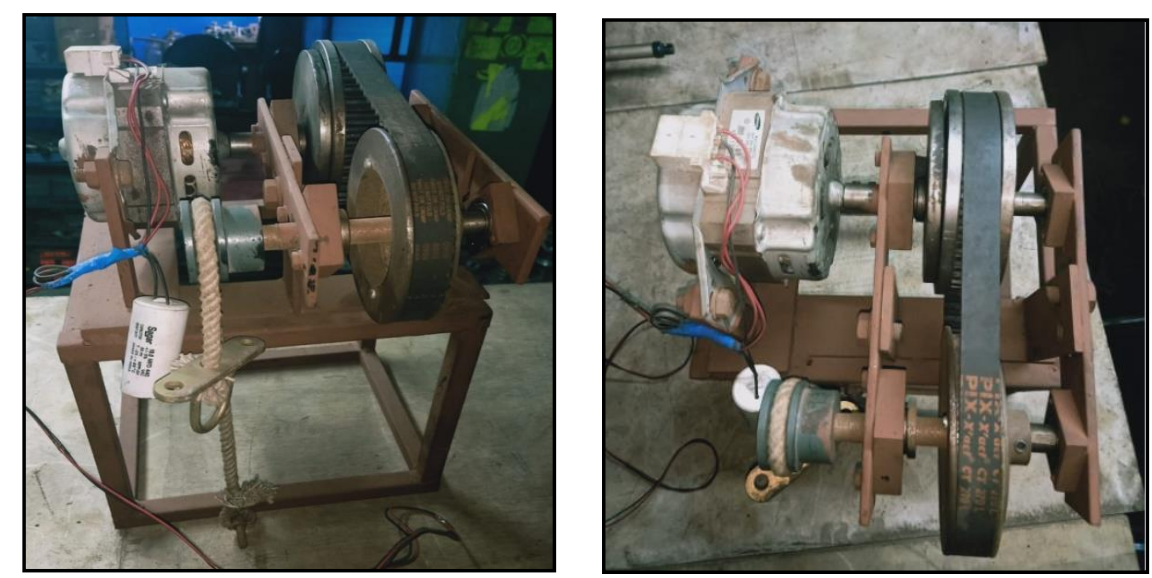

Figure 8: Experimental setup

\subsection{Test Results}

Table 3: Results

\begin{tabular}{|c|c|c|c|c|}
\hline Load $(\mathrm{kg})$ & Speed $(\mathrm{rpm})$ & Torque $((\mathrm{N}-\mathrm{m})$ & Power(watt) & Efficiency (\%) \\
\hline 2 & 1035 & 0.981 & 106.339419 & 57.48076703 \\
\hline 2.5 & 1024 & 0.981 & 105.209242 & 56.86986032 \\
\hline 3 & 1010 & 1.226 & 129.713543 & 70.11542838 \\
\hline 3.5 & 980 & 1.472 & 151.032798 & 81.63935027 \\
\hline 4 & 910 & 1.717 & 163.618865 & 88.44262946 \\
\hline 4.5 & 826 & 1.962 & 169.732097 & 91.74707935 \\
\hline
\end{tabular}

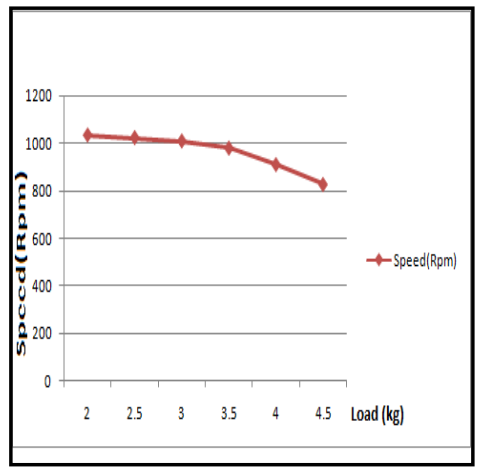

Graph of Load vs. Speed

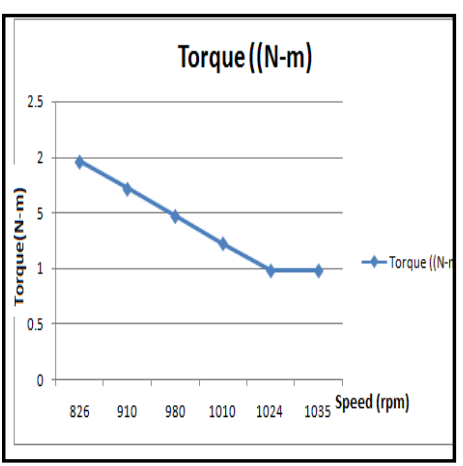

Graph of Torque vs. Speed 


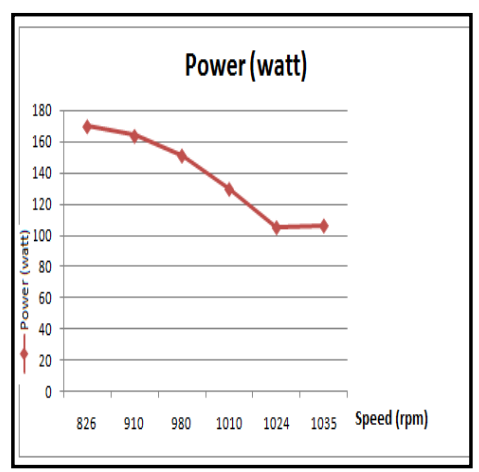

Graph of Power vs. Speed

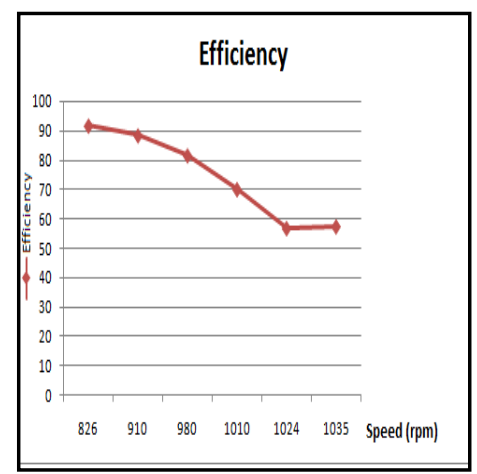

Graph of Efficiency vs. Speed

\section{Conclusion}

1. Maximum stress induced by theoretical method in the input shaft is $2.35 \mathrm{Mpa}$ and the maximum Vonmisses stress determined using Ansys Workbench is $6.76 \mathrm{Mpa}$, both are well below the allowable limit hence the input shaft is safe under torsional load.

2. Maximum stress induced by theoretical method in the Input pulley is $0.15 \mathrm{Mpa}$ and the maximum Vonmises stress determined using Ansys Workbench is $1.61 \mathrm{Mpa}$, both are well below the allowable limit hence input pulley is safe under torsional load

3. The drive torque increases with the drop in speed and maximum torque is observed at speed of 826 rpm.

4. The drive power increases with the drop in speed and maximum power is observed at speed of 826 rpm.

5. The drive efficiency increases with the drop in speed and maximum efficiency is observed at speed of $826 \mathrm{rpm}$.

\section{References}

[1] Govada Tejaswini \& G. Chandra Mohan Reddy, "Compared present technologies of the gearbox and the result of their calculated efficiency", International Journal \& Magazine of Engineering, Technology, Management and Research, Volume No: 2 (2015), Issue No: 7 (July)

[2] Padmanabhan. S., Chandrasekaran. M. and Srinivasa Raman. V., "Design Optimization of Worm Gear drive”, International Journal of Mining, Metallurgy \& Mechanical Engineering (IJMMME), ISSN 2320-4060, Volume 1, Issue 1 (2013).

[3] Chiu-Fan Hsieh "The effect on dynamics of using a new transmission design for eccentric speed reducers", Mechanism and Machine Theory, Volume 80, October 2014, Pages 1-16.

[4] Wan-Sung Lin, "Design of a two-stage cycloidal gear reducer with tooth modifications", Mechanism and Machine Theory, Volume 79, September 2014, Pages 184-197

[5] Hong-Sen Yan \& Ta-Shi Lai, "Geometry design of an elementary planetary gear train with cylindrical toothprofiles”, Volume 37, Issue 8, August 2002, Pages 757-767

[6] G. Domek, "Meshing in Gear with Timing Belts", IACSIT International Journal of Engineering and Technology, ISSN: 1793-8236, Vol.3, No.1, February 2011.

[7] Mr. Naeem B. Tamboli and Prof. Amol S.Todkar, "Modeling, Design, Development, Testing \& Analysis Of Dual Worm Self Locking System For Improved Transmission Efficiency \& Deceleration Locking Property", International Journal Of Innovations In Engineering Research And Technology [IJIERT], Volume 2, Issue 12, Dec.-2015

[8] Bingkui Chen, "Generation and investigation of a new cycloid drive with double contact" Mechanism and Machine Theory Volume 49, March 2012, Pages 270-283. 